\title{
Educação infantil: da medicalização à judicialização do atendimento em creches
}

\author{
Beatriz Fátima Mendes' ${ }^{1}$ Heloisa Helena de Oliveira Azevedo²
}

\section{Resumo}

O presente artigo constitui-se de resultados obtidos em uma pesquisa de mestrado em educação, a qual analisou as influências das decisões judiciais na qualidade do atendimento oferecido à educação infantil em creches municipais situadas em Campinas, São Paulo. A intenção é analisar dados históricos sobre a origem das instituições de educação infantil com vistas à reflexão crítica sobre uma "nova justificativa" para a obrigatoriedade do atendimento à criança pequena: a judicialização. Trata-se de um estudo de natureza qualitativa, cujo material empírico foi produzido mediante entrevistas semiestruturadas e visita in loco. Foi possível perceber que a ação dos juízes ao atender a um direito da criança à educação acaba gerando, ainda que não intencionalmente, outro problema, a superlotação das creches, o que compromete a qualidade do atendimento oferecido. Consideramos, por fim, que para que tal problema seja solucionado, o Poder Público precisa desenvolver ações emergenciais sob pena de contínuo agravamento do problema. Tomamos como base para nossa análise um referencial teórico crítico sobre educação infantil.

\section{Palavras-chave}

Creche. Educação Infantil. Trabalho Pedagógico. Decisões Judiciais. Formação de Professores.

1. Mestre em Educação pela Pontifícia Universidade Católica de Campinas, São Paulo, Brasil. E-mail: beatrizmendes@zipmail.com.br.

2. Doutora em Educação pela Universidade Metodista de Piracicaba, São Paulo, Brasil; professora titular da Pontifícia Universidade Católica de Campinas, São Paulo, Brasil. E-mail: hhazevedo79@gmail.com. 


\title{
Child education: from medicalization to judicialization of day cares attendance
}

Beatriz Fátima Mendes*, Heloisa Helena de Oliveira Azevedo**

\begin{abstract}
The present article is about obtained results in a master degree research in education, which has analyzed the influences of judicial decisions in the care quality offered to the child's education in the city's day care centers located in Campinas, State of São Paulo, Brazil. It aimed to analyze the historical data about child's education institutions origins in order to obtain a critical reflection about a "new justification" for the need of small child's care: the judicialization. It is a qualitative study approach, in which the empirical material was produced through semi structured interviews and in loco visit. It was possible to realize that the judge's actions to comply with the children's right to the education turns out to create, although not intentionally, another issue: the overcrowding of the day care centers, which causes an unsatisfied service quality. We considered, in the end, in order to have to a solution to this problem, the Public Power must develop emergency actions, under penalty of continuous aggravation of the problem. We based our analysis in a critical theoretical referential about child's education.
\end{abstract}

\section{Keywords}

Day Care Centers. Child Education. Pedagogical Work. Judicial Decisions. Teacher's Formation.

\footnotetext{
* MSc in Education, Pontifical Catholic University of Campinas, State of São Paulo, Brazil. E-mail: beatrizmendes@ zipmail.com.br.

** PhD in Education, Metodist University of Piracicaba, State of São Paulo, Brazil; professor at Pontifical Catholic University of Campinas, State of São Paulo, Brazil. E-mail: hhazevedo79@gmail.com.
} 


\section{Introdução}

A história da infância brasileira, no âmbito das classes sociais menos favorecidas social e economicamente, se caracterizou por momentos de grandes dificuldades, no que se refere à sua guarda e proteção. Nos séculos passados, as crianças que eram renegadas por suas famílias, por exemplo, por serem filhos de mães solteiras ou porque ficavam órfãs, eram colocadas em um lugar para que fossem protegidas e não viessem a óbito. Esse lugar era chamado de Roda dos Excluídos; um dispositivo assistencial que existiu em alguns países da Europa e foi trazido para o Brasil no século XVIII. A criança era colocada dentro de uma caixa giratória que ficava do lado de fora, acoplada ao muro da instituição, tocava-se a campainha e a pessoa que estava do lado de dentro rodava a roldana para que a caixa com a criança fosse para o lado interno da instituição. Em São Paulo, a Roda dos Excluídos existiu até o ano de 1948. Apenas no final do século XIX surgem as primeiras leis de proteção jurídica e as primeiras alternativas de atendimento institucionalizadas.

Posteriormente, no Brasil, já no século XX, com o aumento de demanda por mão de obra na área industrial, a partir da década de 1960 e com a inserção da mulher no mercado de trabalho, se tornou necessário haver instituições que acolhessem as crianças enquanto seus pais trabalhavam. Foram, então, criadas as primeiras instituições que resguardavam fisicamente a criança enquanto seus pais trabalhavam. Ou seja, neste momento o objetivo do atendimento oferecido era somente para que a saúde física dela fosse preservada. Noutras palavras, era um atendimento essencialmente assistencial e higienista que visava apenas cuidar para que as condições de vida insalubres das crianças pobres não oferecessem riscos de epidemia de doenças para a população em geral, caso não fossem tratadas, uma vez que, pela sua condição social estavam mais vulneráveis a essas situações. Sendo assim, a preocupação em atendêlas era principalmente uma questão de saúde pública, ainda que também fosse de guarda das crianças para que seus pais pudessem ter onde deixá-las para irem trabalhar. O discurso médico de preocupação com a precariedade de vida das camadas populares e da sua marginalização cultural estabelece como objetivo da educação a compensação das carências biopsicossociais apresentadas no desenvolvimento da criança, de forma a prepará-la para que não fracassasse nas etapas escolares posteriores (AZEVEDO, 2013).

O contexto de desenvolvimento econômico do país fazia com que a necessidade de mão de obra crescesse cada vez mais, e é nesse contexto que a sociedade começa a organizar suas ações em prol de melhores condições de atendimento dos filhos dos trabalhadores operários. Segundo Farias (1999), a fim de atender reivindicações do movimento operário, algumas indústrias criam creches para o atendimento dessas crianças. Mesmo assim, as pressões operárias continuaram com o passar dos anos, chegando a exigir do Estado a criação de creches independentes das indústrias e parques infantis.

O Estado, interessado e incentivador dessa prática, normatiza esse atendimento com a citação do mesmo no primeiro documento nacional voltado a educação no Brasil, qual seja, a Lei de Diretrizes e Bases da Educação Nacional de 1961. A LDB/1961 traz em seu Capítulo I, nos respectivos artigos, as normas relacionadas ao atendimento às crianças. Nesse primeiro momento de normatização das instituições de atendimento à infância, a lei é superficial, deixando ainda indefinido o conceito de educação infantil, aspectos e caminhos que serem tomados. Portanto, em razão desta origem da 
creche, ainda hoje, ela é vista apenas como uma instituição assistencial para os filhos das camadas mais pobres da sociedade. Todavia, com as conquistas históricas no âmbito legal ${ }^{3} \mathrm{e}$ o avanço no conhecimento científico sobre o desenvolvimento humano, tornou-se possível maior reconhecimento do papel da creche na vida da criança, enquanto lugar de aprendizagem e desenvolvimento, e não apenas de guarda e cuidados com a saúde física das crianças.

As primeiras creches criadas no Brasil, que datam do ano de 1889, tinham a função de cuidar das crianças para que os pais pudessem trabalhar sabendo que seus filhos estavam em uma instituição que zelava pela saúde deles. A creche era vista como um lugar em que a criança seria protegida, por isso, era considerada uma instituição assistencial. Em um primeiro momento, as crianças eram assistidas por instituições de caráter médico.

\begin{abstract}
Assim, a medicalização da assistência à criança até seis anos, por um lado, e a psicologização do trabalho educativo, por outro lado, imbuídos de uma concepção abstrata de infância, foram a ênfase da etapa pré-1930. Além disso, o surgimento de um Estado que se pretendia forte e autoritário acarretava uma maior preocupação com a massa de crianças brasileiras consideradas não aproveitadas. $\mathrm{O}$ atendimento sistemático às crianças significava uma possível utilização e cooptação destas em benefício do Estado. (KRAMER, 1995, p. 55-56).
\end{abstract}

Por um longo período, do surgimento das creches até a institucionalição da educação infantil pela Constituição Federal e pela Lei de Diretrizes e Bases da Educação Nacional (LDB no 9.394/96), a proteção à criança esteve muito entrelaçada à questão médica, ou seja, o foco do atendimento estava centrado em sua saúde física. Por isso, muitas vezes, as instituições que atendiam esse público eram de caráter médico, pois se preocupavam apenas com o aspecto orgânico da criança, se as vacinas estavam em dia, se a saúde odontológica estava boa etc.

Um dos motivos para a criação de instituições que atendessem as crianças era a questão sanitarista, também em razão da alta taxa de mortalidade infantil existente no início do século XX. No começo, a função dessas instituições era, principalmente, médicosanitarista.

No início do século $X X$, para acompanhar a tendência mundial de todo capitalismo, da crescente urbanização e da necessidade de reprodução da força de trabalho, as creches aparecem como fruto dos movimentos operários e da preocupação médicosanitarista com as condições de vida das populações mais pobres. De fato, no Brasil, as creches surgem para contribuir na produção de seres capazes, higiênicos, nutridos e sem doenças. Em decorrência disso, as poucas creches criadas nesse momento situavamse, sobretudo, nas vilas operárias e eram mantidas, principalmente, por entidades filantrópicas e, em menor número, pelo Estado. O trabalho desenvolvido nas creches era, fundamentalmente, assistencial. Segundo Oliveira, Mello, Vitória e Rossetti-Ferreira (1999), a preocupação era com a alimentação, higiene e segurança física das crianças. Um trabalho voltado para a educação e para o desenvolvimento da criança não era, nessa época, valorizado. (PACHECO; DUPRET, 2004, p. 104).

Somente com a promulgação de uma nova Lei de Diretrizes e Bases da Educação

3. A Constituição Federal de 1988, em seu artigo 208, inciso IV, I dispõe: “O dever do Estado com a educação será efetivado mediante a garantia de: [...] IV - educação infantil, em creche e pré-escola, às crianças até cinco anos de idade"); a Lei n. 8.069/90 - Estatuto da Criança e do Adolescente (ECA) em seu artigo 54 dispõe: "É dever do Estado assegurar à criança e ao adolescente: [...] IV - atendimento em creche e pré-escola às crianças de zero a cinco anos de idade"), a Lei de Diretrizes e Bases da Educação Nacional (LDBEN - Lei n 9.394/96) em seu artigo $4^{\circ}$, inciso II dispõe: "O dever do Estado com educação escolar pública será efetivado mediante a garantia de: [...] II - educação infantil gratuita às crianças de até cinco anos de idade". 
Nacional, Lei 9.394/1996, é que a creche passou a ser responsabilidade do setor educacional no Brasil. A Constituição da República de 1988 previu expressamente o direito das crianças de até seis anos de idade à educação e a LDB enfatizou a importância da educação infantil enquanto primeira etapa da educação básica, estabelecendo que esta fosse oferecida em creches para as crianças de zero a três anos. Nesse contexto, começa-se a perceber a importância da creche na vida da criança, tanto para seu desenvolvimento quanto para sua aprendizagem. Com a vigência dessas normas, a importância desse espaço na vida da criança ganha relevância.

De acordo com Azevedo (2013), o atendimento oferecido à criança em diferentes épocas está vinculado à concepção que determinada sociedade tinha dela em cada momento.

\begin{abstract}
Nãodiriaque "avançamos" ou que "evoluímos" em nosso modo de pensar a criança, mas que "acompanhamos" as transformações que as sociedades foram vivendo em termos políticos e sociais, o que torna inescapável a modificação de nossa maneira de pensá-la [...]. Consequentemente, nossa maneira de lidar com ela também mudou. Se no início se pensava em apenas "cuidar" delas, mais tarde se propôs "educá-la", em resposta às transformações e exigências políticas que se faziam, provocando uma dicotomia nesse atendimento em termos sociais, ou seja, às crianças das classes populares era oferecido atendimento assistencial (cuidar) e às da elite se oferecia atendimento educacional (educar), de aprendizado de leitura, escrita e conteúdos escolares. Essa separação também se dava pela idade das crianças, oferecendose ás de zero a três anos apenas cuidado e às de quatro a seis, educação, nos moldes escolares (AZEVEDO, 2013, p. 67-68).
\end{abstract}

A situação atual do atendimento à criança de até cinco anos ${ }^{4}$ de idade, em todo o país, é resultado de muitas lutas e reivindicações pelo reconhecimento dos direitos das crianças nos vários âmbitos da vida da sociedade (político, assistencial, médico, jurídico e educacional).

A educação infantil é uma etapa muito importante na formação do indivíduo, pois é por meio dela que a criança se inicia na vida escolar e também começa a ter a educação formal, no sentido da educação oferecida nas instituições de ensino, autorizadas pelo Poder Público, e que atuam com base na Constituição Federal, na Lei de Diretrizes e Bases da Educação Nacional e nos demais documentos oficiais emitidos pelas instâncias federal, estaduais e municipais. É, acima de tudo, um direito que precisa ser garantido.

\section{Bases legais do atendimento infantil}

A educação brasileira passou por diversas mudanças ao longo do tempo. A Constituição da República, já em 1934, previa expressamente a educação como um direito de todos e um dever do Estado oferecê-la. Nos termos da atual Constituição, de 1988, conforme dispõe o Art. 205: "A educação, direito de todos e dever do Estado e da família, será promovida e incentivada com a colaboração da sociedade, visando o pleno desenvolvimento da pessoa, seu preparo para o exercício da cidadania e sua qualificação para o trabalho" (BRASIL, 1998).

A estrutura da educação básica no Brasil está organizada nas seguintes etapa/níveis de ensino: educação infantil, ensino fundamental e ensino médio. A educação infantil é oferecida às crianças de zero a cinco anos; o ensino fundamental, às de seis a catorze anos; e o ensino médioàsadolescentesdequinzea dezesseteanos.

De acordo com o Art. 29 da Lei de Diretrizes e Bases da Educação de 1996, a educação infantil, primeira etapa da educação básica, tem como finalidade "o desenvolvimento

4. Atualmente, a Educação Infantil atende a criança de até cinco anos. Essa alteração foi feita pela Lei $n^{\circ}$ 11.274/2006, que inseriu as crianças de seis anos no ensino fundamental. 
integral da criança de até cinco anos, em seus aspectos físico, psicológico, intelectual e social, a fim de complementar a ação da família e da comunidade" (BRASIL, 1996). Outro documento oficial que se refere à atenção às crianças é o Estatuto da Criança e do Adolescente (ECA), que reforça a obrigatoriedade do oferecimento da educação infantil, conforme disposto no Art. 54: "É dever do Estado assegurar à criança e ao adolescente: IV atendimento em creche e pré-escola às crianças de zero a seis anos de idade" (BRASIL, 1990).

OECA estipula, ainda, que, além da criança ter o direito à creche, tem direito a que esta seja próxima a sua residência, conforme Art. 53:

A criança e o adolescente têm direito à educação, visando ao pleno desenvolvimento de sua pessoa, preparo para o exercício da cidadania e qualificação para o trabalho, assegurando-se lhes: [...] $\mathrm{V}$ - acesso à escola pública e gratuita próxima de sua residência.

A competência de ofertar e fiscalizar a educação infantil oferecida nas creches é de responsabilidade dos municípios, conforme previsão constitucional e legal. De acordo com o Art. 211, § 2o, da Constituição Federal: "Os Municípios atuarão prioritariamente no ensino fundamental e na educação infantil". E o Art. 11, da LDB/1996 complementa:

Os Municípios incumbir-se-ão de: [...] V - oferecer a educação infantil em creches e pré-escolas, e, com prioridade, o ensino fundamental, permitida a atuação em outros níveis de ensino somente quando estiverem atendidas plenamente as necessidades de sua área de competência e com recursos acima dos percentuais mínimos vinculados pela Constituição Federal à manutenção e desenvolvimento do ensino.

Portanto, a educação infantil será oferecida para as crianças de zero a três anos em creches. A creche, conforme estabelecem os documentos oficiais até o momento editados em nosso país, é uma instituição educacional e as crianças brasileiras passam a ter direito a esse atendimento educacional a partir da Constituição Federal de 1988. Em razão de como ocorreu o surgimento das creches é que podemos compreender na atualidade porque ela ainda é vista como uma instituição assistencial.

\section{Matrícula via decisões judiciais: direito à educação ou educação de qualidade?}

Com base nas entrevistas semiestruturadas realizadas com os profissionais de creches (diretor e professor) e com os demais sujeitos que estão diretamente ligados com a questão judicial da falta de vagas em creches $^{5}$ e, considerando a realidade observada (vista in loco) na creche, é possível considerar que os profissionais de creches, diretores, professores, monitores e demais funcionários não existem em número suficiente para atender a demanda, principalmente em razão das matrículas que são feitas via decisões judiciais que extrapolam a capacidade de atendimento adequado pela instituição. A fala a seguir da Diretora da creche analisada revela essa realidade.

Quais idades são as mais solicitadas?

Sempre, desde que eu entrei na rede de Campinas é para o Agrupamento I que eles chamam, ainda tem a denominação deles é berçário, é a maior procura. A minha maior lista de espera, a minha lista de demanda é o berçário. [...] pra que esse atendimento aconteça da melhor forma possível, esses profissionais que atendem diretamente a criança, tanto para a Prefeitura, Secretaria da Educação, quanto os outros entes, seja Conselho Tutelar, Ministério Público, porque a gente que acata as decisões, eu não tenho

5. Juiz de Direito atuante na Vara da Infância e da Juventude da Comarca de Campinas, São Paulo, Promotor de Justiça atuante na Vara da Infância e da Juventude da Comarca de Campinas, São Paulo e pai de aluno. 
poder de decidir, eu tenho que acatar essa decisão que vem do Ministério Público, hoje não vem direito na creche [...] (Diretora da Creche).

Conforme informações por nós solicitadas, no primeiro semestre de 2015, e que nos foram enviadas via e-mail pelo Cartório da Vara da Infância e da Juventude da Comarca de Campinas, percebemos que, nos últimos anos, o número de liminares ${ }^{6}$ determinando a matrícula da criança na creche aumentou significativamente, conforme podemos verificar na tabela apresentada na Tabela 1.

Tabela 1 - Liminares concedidas em ações pleiteando vagas em creches.

\begin{tabular}{cc}
\hline Número de liminares & Ano \\
\hline 1.021 (até 07/04/2015) & $2015-1$ o Semestre \\
1.382 & $2014-2$ o Semestre \\
1.431 & $2014-1$ o Semestre \\
578 & $2013-2$ o Semestre \\
500 (número aproximado) & $2013-1$ o Semestre \\
\hline
\end{tabular}

Fonte: Dados fornecidos pela Vara da Infância e da Juventude da Comarca de Campinas-SP, adaptado pelas autoras (2016).

Ao analisarmos os dados fornecidos pela creches públicas no município é excessivo em Prefeitura Municipal de Campinas, São Paulo, relação à capacidade real de atendimento das percebemos que o número de falta de vagas em instituições, conforme apresentamos na Tabela 2:

Tabela 2 - Número de falta de vagas em creches públicas do município de Campinas, São Paulo.

\begin{tabular}{lc}
\hline Ano & Número de vagas faltantes \\
\hline 2012 & 9.375 \\
2013 & 10.545 \\
2014 & 10.528 \\
2015 & 8.744 \\
2016 & 8.745 \\
\hline
\end{tabular}

Fonte: Dados fornecidos pela Secretaria Municipal de Educação de Campinas-SP, adaptado pelas autoras (2016).

6. Liminares são decisões dadas no início do processo judicial. "Salienta-se que a expressão 'liminar' indica apenas o momento processual em que a medida pode ser concedida. Assim, quando o autor formular pedido liminar, está pleiteando que a medida cautelar lhe seja concedida previamente" (FIGUEIREDO; SÁ, 2011). 
Em razão da tabela acima, podemos observar que há anos ocorre tal situação no município de Campinas, São Paulo. É possível também verificar que, com o passar dos anos, a falta de vagas aumentou, o que fez com que o número de liminares que concedem a vaga em creche aumentasse, por sua vez levando ao aumento da superlotação. Ou seja, é um problema antigo e que não foi resolvido, ou sequer, minimizado até os dias de hoje. Com a superlotação não há espaço adequado para atender todas as crianças, não há quantidade de materiais e de brinquedos suficiente para todos, não há quantidade de profissionais necessários em relação à quantidade de alunos.

A população de crianças de zero a três anos aumentou muito nos últimos anos e o Poder Público não acompanhou esse crescimento em relação à oferta de vagas em creches. Diante dessa realidade, ele terá que desenvolver ações emergenciais para resolver essa situação caótica, que tende a piorar ainda mais se nenhuma providência for tomada. Dado importante é que não só aumentou do número de crianças, mas também a consciência das famílias no que se refere aos procedimentos de como conseguir vagas para seus filhos nas creches via decisão judicial. Conforme nos respondeu um pai ao ser inquirido sobre como conseguiu a vaga para seu filho na creche:

Tive que colocar um advogado pra mim poder entrar na creche. Porque eu acho assim, como eu moro aqui perto, o certo é quem mora aqui perto ter a preferência. [...] Foi um absurdo, né, ter que entrar [...] a creche aqui do lado tive que entrar na justiça para conseguir a vaga. Só assim consegui a vaga. Quando eu vim aqui tinha não sei quantas pessoas na minha frente, eu entrei com o advogado já arrumei a vaga direto. Eu acho assim que podia ter uma quantidade de vaga assegurada para as pessoas que moram aqui perto, da região, ter preferência, não só eu, mas outras pessoas, entendeu? (Pai de aluno).

A história do atendimento infantil institucionalizado passou por várias nuances até o mesmo ser considerado educacional, do ponto de vista formal, e a sua importância na educação da criança ser reconhecida pelo poder público, pelos profissionais da educação, pela sociedade e principalmente pelos pais dos alunos.

Diante disso, consideramos de fundamental importância que a criança frequente a creche, não apenas como atenção ao seu direito à educação, mas, e, principalmente, como lugar da formação inicial de sujeitos que já fazem parte de uma sociedade. Esse lugar de aprendizagem e desenvolvimento por sua vez, exige profissionais qualificados. Esse é outro grande desafio enfrentado nessa etapa educativa, além da escassez de vagas para todas as crianças que a elas têm direito.

A Constituição Federal de 1988 é considerada a nossa lei maior, porque todas as demais leis devem estar em consonância a ela. O Art. $2^{\circ}$, da Constituição Federal prevê que os poderes (legislativo, executivo e judiciário) são independentes e harmônicos ${ }^{7}$ entre si, no entanto, isso não impede que um interfira no outro para que os direitos fundamentais nela previstos sejam respeitados; não só o direito à educação, mas qualquer direito fundamental, como o direito à vida ou à saúde.

Uma vez que o Poder Público (Poder Executivo) não proporciona meios para que o direito à educação infantil seja efetivado, o Poder Judiciário deve intervir para a efetivação desse direito, já que a norma que prevê o direito à educação infantil em nossa Carta Magna é um direito fundamental que deve

7. "Extrai-se da expressão 'independentes e harmônicos' a teoria dos freios e contrapesos (checks and balances), de origem estadunidense, segundo a qual os Poderes, ao mesmo tempo em que estão impedidos de invadir a esfera de competência dos demais, devem atuar de forma integrada, inclusive controlando-se reciprocamente" (RUSSO, 2011). 
ser garantido. Trata-se de norma de eficácia plena, porque ela não precisa de nenhuma outra norma para regulamentá-la e direito fundamental subjetivo por ser um direito inerente ao ser humano. É o que nos esclarece o Promotor de Justiça por nós entrevistado:

As creches não estão superlotadas por conta das decisões judiciais, elas estão superlotadas porque o Poder Público se omitiu ao longo dos anos e não abriu o número de vagas em creches necessário, que a população precisa [...] o Judiciário tá apenas atendendo um direito da criança, né? Então cabe ao Poder Público se estruturar melhor pra dar vazão a essa demanda, essa necessidade, por que o que se espera, o que o Juiz vai fazer? Vai deixar de conceder o direito pra criança? Olha, eu não vou conceder o direito porque o Poder Público não construiu a creche. Se o Juiz fizesse isso estaria completamente equivocado, sim, justamente por ser um direito fundamental ele tem que efetivar. (Promotor da Vara da Infância e da Juventude da Cidade de Campinas/SP).

$E$, justamente pelo fato de o direitoà creche estar previsto em uma norma constitucional de eficácia plena, não há discricionariedade ${ }^{8}$ por parte do Poder Público em oferecer vagas em creches para as crianças. No entanto, ele pode fazer isso de várias maneiras, por exemplo, pode construir novas creches, aumentar os convênios e, em caráter emergencial, colocar as crianças em creches particulares. Enfim, como fazer para que este direito seja respeitado é ele que decide, no entanto, o direito tem que ser efetivado. Muitas vezes o Poder Público alega falta de recursos para a realização desse direito, alega o que chamamos de reserva do possível, ou seja, a efetivação dos direitos está condicionada as possibilidades do Estado. No entanto, o próprio STF (Supremo Tribunal Federal) reconheceu que no caso de aumento de vagas em creches não há que se falar em reserva do possível. A reserva do possível não pode se sobrepor ao mínimo existencial (vida, saúde, educação, trabalho), o mínimo para que o ser humano possa viver com dignidade.

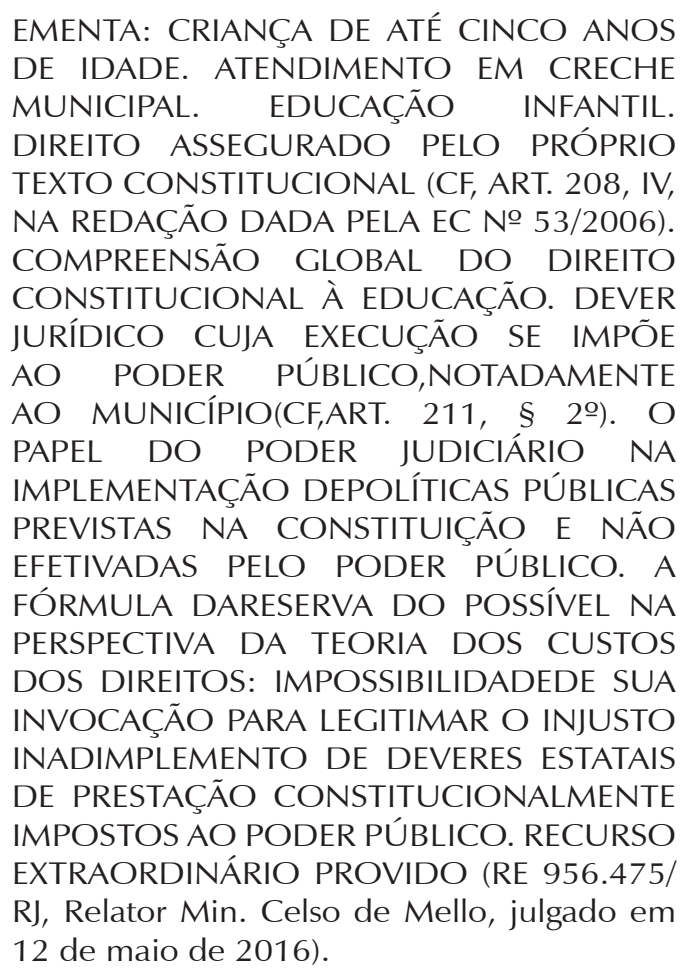

Sendo assim, uma vez que o pai ou responsável não consegue matricular seu filho em uma creche municipal por falta de vaga, se recorrer ao Poder Judiciário, terá uma decisão liminar determinando a matrícula de seu filho na determinada creche, pois se trata de direito à educação infantil. Na visão do Promotor da Vara da Infância e da Juventude da Cidade de Campinas, São Paulo,

Então o que é que acontece né [...] há uma pressão muito grande de um lado daqueles pais ou responsáveis de crianças que estão fora das creches e que querem o acesso à vaga em creche. Direito estabelecido ai em diversos diplomas legais, Constituição, ECA, LDB e

8. Liberdade na escolha segundo os critérios de conveniência, oportunidade e justiça, próprios da autoridade, observando sempre os limites estabelecidos em lei, pois estes critérios não estão definidos em lei. 
por ai vai né. Existe sim uma peculiaridade no caso desse direito que é assim ele se manifesta, ele se coloca a partir de que o pai, a mãe ou responsável manifesta o desejo de colar o filho ou a filha na creche, manifestou o desejo ele tem esse direito à vaga, a criança tem esse direito.

Todavia, quando há uma superlotação das creches porque muitas crianças foram matriculadas em razão das decisões judiciais, a qualidade da educação infantil ali oferecida fica comprometida. Até porque é humanamente impossível os profissionais de creches cuidarem e educarem uma quantidade imensa de crianças, conforme nos relata uma professora:

É um direito da criança participar da escola. Tem leis que protegem. Eu não tenho uma opinião. É direito da criança. E quando essas decisões geram o aumento da superlotação, mesmo a superlotação na sala de aula, no que isso influi diretamente nas suas condições de trabalho? É, as crianças demandam atenções, então um grupo grande de crianças na sala, você tem uma quantidade restrita de adultos que pode atrapalhar no desenvolvimento da rotina né, e quando acontece isso, crianças a mais, a gente registra no livro de ocorrências da escola que a frequência passou do que é pela Resolução, pelo módulo de adultocriança. [...] 24 é considerado normal pelo tamanho da sala também, que a minha sala, não adianta ter um número muito grande de crianças porque eu não tenho espaço para colocar eles pra dormir. Então isso acaba impactando também nas estruturas que a gente tem. Tem nosso espaço do refeitório, que a gente precisa para atender as crianças. Aqui a creche tem espaço restrito. (Professora de crianças do Agrupamento I - 3 meses a 1 ano e 5 meses).

Se tomarmos como referência para estabelecer critérios de qualidade um documento oficial do Ministério da Educação intitulado "Critérios para um atendimento em creches que respeite os direitos fundamentais das crianças", a situação acima descrita pela professora revela que não há condições adequadas de atendimento que respeite a dignidade e os direitos básicos das crianças:

Embora muitos dos itens incluídos apliquemse também a outras modalidades de atendimento, como a pré-escola, a qualidade da educação e do cuidado em creches constitui o objeto principal do documento. Atingir, concreta e objetivamente, um patamar mínimo de qualidade que respeite a dignidade e os direitos básicos das crianças, nas instituições onde muitas delas vivem a maior parte de sua infância, nos parece, nesse momento, o objetivo mais urgente. (BRASIL, 2009, grifos nossos).

As crianças que frequentam as creches passam muitas horas por dias nesse ambiente, sejam nas creches de meio período, sejam nas de período integral, por isso elas precisam de uma infraestrutura adequada, com espaço físico amplo em relação ao número de crianças, com boas condições de higiene, com materiais e brinquedos suficientes e com uma quantidade suficiente de funcionários. O documento supramencionado também apresenta os critérios necessários para a creche ser considerada como aquela que respeita a criança, são eles:

Nossas crianças têm direito à brincadeira - Nossas crianças têm direito à atenção individual • Nossas crianças têm direito a um ambiente aconchegante, seguro e estimulante

- Nossas crianças têm direito ao contato com a natureza - Nossas crianças têm direito a higiene e à saúde • Nossas crianças têm direito a uma alimentação sadia - Nossas crianças têm direito a desenvolver sua curiosidade, imaginação e capacidade de expressão • Nossas crianças têm direito ao movimento em espaços amplos • Nossas crianças têm direito à proteção, ao afeto e à amizade • Nossas crianças têm direito a expressar seus sentimentos - Nossas crianças têm direito a uma especial atenção durante seu período de adaptação à creche • Nossas crianças têm direito a desenvolver sua identidade cultural, 
racial e religiosa. (BRASIL, 2009, p. 17).

A creche é de fundamental importância para o aprendizado e desenvolvimento da criança. No entanto, não basta apenas ela ser matriculada e frequentar a creche, é importante que a educação ali oferecida seja de qualidade. É o que nos relata a professora entrevistada:

O ideal é 20 crianças, porque a gente consegue ter um trabalho mais de atenção, cuidado, a parte pedagógica também muito melhor, do que quando passa isso. As crianças menores precisam de espaço, quando vêm muitas crianças, na época que eu já tive 25, 26, o que acontece?, eles mordem, eles batem, puxam o cabelo, porque eles precisam desses espaços para circular, então acontece bastante isso, não que os menores, a frequência quando está baixa não acontece, acontece, mas quando tá muito, passou do 24 , eles começam a ficar muito agitados, eu acho que pelo choro também, porque como têm crianças bebês de 5 meses até crianças de 2 anos, então eles acabam ficando mais irritados, acho que com o barulho, então acaba influenciando bastante. (Professora de crianças do Agrupamento I - 3 meses a 1 ano e 5 meses).

Em razão das decisões judiciais que determinam as matrículas das crianças nas creches vivenciamos o fenômeno chamado "judicialização" da educação infantil. O oferecimento da educação infantil é competência do Poder Executivo. Ele que tem obrigação de oferecer as vagas em creches para as crianças de 0 a 3 anos de idade. No entanto, no momento em que o Poder Judiciário precisa interferir para que o direito à educação infantil em creches seja efetivado, ocorre o que chamamos de "judicialização da educação infantil", sendo ela necessária para que o direito à educação infantil em creches seja efetivado.

Sendo assim, embora historicamente tenhamos alcançado conquistas importantes, no que se refere ao atendimento à criança pequena, apenas mudamos nosso parâmetro para o estabelecimento da obrigatoriedade desse atendimento, ou seja, se no início o atendimento tinha uma justificativa "médica" hoje ele tem uma justificativa "judicial", o que nos revela o quanto ainda precisamos avançar no âmbito pedagógico desse atendimento, pois tanto numa justificativa quanto noutra não é "a criança" em suas necessidades educacionais que está sendo considerada como prioridade nesse atendimento. Em outras palavras, seu direito à educação não está sendo atendido plenamente.

\section{Considerações finais}

A história do atendimento à criança pequena traz marcas indeléveis que até hoje se constituem obstáculos a um atendimento digno e que respeite efetivamente o direito da criança à educação. De local onde as crianças ficavam para serem cuidadas, para terem a saúde física preservada, sendo uma questão simplesmente médica, higienista, hoje a educação infantil conquistou legalmente seu lugar de importância na educação escolar inicial das crianças, se tornou a primeira etapa da educação básica. No entanto, nesse percurso histórico, nos deparamos com uma realidade que atinge especialmente as crianças de 0 a 3 anos de idade: a falta de vagas em creches. A partir desse momento, o Poder Judiciário precisou intervir para que fosse assegurado o direito à creche às crianças de 0 a 3 anos, quando da negação da matrícula da criança na creche. É o que denominamos de "judicialização" do direito à creche, pois em muitos casos o direito à creche só é efetivado por meio de decisão do Poder Judiciário.

A falta de vagas em creches é um problema que vem ocorrendo há tempos e com o passar dos anos só aumentou. A nossa Lei Maior dispõe que a educação infantil de 0 a 3 anos, a ser oferecida em creches, é obrigatória. Na tentativa de se efetuar esse direito, os Juízes, por meio de decisões judicias, 
determinam, obrigatoriamente, as matrículas das crianças. No momento em que há a negação dessa matrícula na creche, e os pais/ responsáveis pela criança precisam ingressar com a ação judicial para que o direito de seu filho seja efetivado, ocorre a judicialização do atendimento na educação infantil. Esta realidade de obtenção de vagas nas creches gerou outro problema: a superlotação das creches, o que, por sua vez, compromete a qualidade do atendimento oferecido às crianças. Em razão dessa superlotação, não há espaço físico, a higienização do ambiente fica comprometida, não há quantidade de materiais e brinquedos adequada e não há profissionais suficientes para atender toda essa demanda de crianças. Perguntamos então, essa condição de atendimento também não põe em risco a saúde das crianças? Se na sua origem as instituições de atendimento infantil tinham esse objetivo, podemos dizer que hoje ele é totalmente desconsiderado em função de outra demanda que esse tempo histórico nos impõe: o grande número de crianças que necessita desse atendimento e deveria tê-lo garantido pelo Poder Público e, como pudemos constatar, não o tem.

Consideramos por fim que, para que o problema da superlotação das creches seja solucionado ou pelo menos minimizado, o Poder Público tem que atuar de forma emergencial, seja construindo novas creches, ampliando os espaços físicos nas já existentes, criando convênios com instituições particulares ou até comprando vagas em creches particulares, ou seja, o Poder Público (Poder Executivo) possui discricionariedade para resolver a questão de falta de vagas em creches, mas ele tem que atuar para que toda a população de 0 a 3 anos seja matriculada e frequente a creche em condições de dignidadee respeito ao seu direito à educação, do contrário, as instituições de educação infantil voltam a ser meros depósitos de crianças.

\section{Referências}

AZEVEDO, H. H. O de. Educação infantil e formação de professores: para além da separação cuidar-educar. São Paulo: Editora da Unesp, 2013.192 p.

BRASIL. Constituição da República Federativa do Brasil. Brasília, DF: Senado Federal, 1988.

. Estatuto da Criança e do Adolescente. Lei no 8.069, de 13 de julho de 1990. Dispõe sobre o Estatuto da Criança e do Adolescente e dá outras providências. Brasília, DF, 1990. Disponível em: <http://www.planalto.gov.br/ccivil_03/leis/L9394.htm>. Acesso em: 2 jul. 2016.

. Lei de Diretrizes e Bases da Educação Nacional. Lei no 9.034, de 20 de dezembro de 1996. Estabelece as diretrizes e bases da educação nacional. Brasília, DF, 1996. Disponível em: <http://www.planalto.gov.br/ccivil_03/leis/L9394.htm>. Acesso em: 2 jul. 2016.

. Ministério da Educação. Secretaria de Educação Básica. Critérios para um atendimento em creches que respeite os direitos fundamentais das crianças. Brasília, DF: MEC, 2009. Disponível em:<http://portal.mec.gov.br/dmdocuments/direitosfundamentais.pdf $>$. Acesso em: 10 out. 2016.

FARIAS, M. de L. S. O. Revelando a instância da letra. Revista da Academia de Letras da Bahia, Salvador, v. 1, p. 189-197, 2005.

FIGUEIREDO, S. D. C.; SÁ, R. M. de. Direito processual civil - teoria geral: do processo e processo 
do conhecimento. 3. ed. São Paulo: Saraiva Jurídicos, 2011. 288 p.

FURTADO, M. A. Concepções de creche em artigos acadêmicos publicados nos períodos nacionais A1 e A2 da área da educação. 2014. 157 f. Dissertação (Mestrado em Educação) Faculdade de Educação, Universidade de Brasília, Distrito Federal, 2014.

KRAMER, S. A política do pré-escolar no Brasil: a arte do disfarce. 5. ed. São Paulo: Cortez, 1995. $140 \mathrm{p}$.

PACHECO, A. L. P. de B.; DUPRET, L. Creche: desenvolvimento ou sobrevivência. Psicol. USP, São Paulo, v. 15, n. 3, p. 103-116, 2004. Disponível em: < https://www.revistas.usp.br/psicousp/article/ view/42285/45958>. Acesso em: 5 jul. 2016.

RUSSO, L. Direito constitucional. 4. ed. São Paulo: Saraiva, 2011. 280 p.

Submetido em 14 de março de 2017.

Aprovado em 15 de maio de 2017. 